\title{
Surveillance of leishmaniases in France, 1999 to 2012
}

L Lachaud ${ }^{1}$, J P Dedet ${ }^{1}$, P Marty ${ }^{2}$, F Faraut ${ }^{3}$, P Buffet ${ }^{4}$, J P Gangneux 5 , C Ravel ${ }^{1}$, P Bastien (patrick.bastien@univ-montp1.fr) ${ }^{1}$, the Working Group for the Notification of Human Leishmanioses in France ${ }^{6}$

1. Centre Hospitalier Universitaire (Academic Hospital Centre) / University Montpellier 1, Laboratoire de ParasitologieMycologie, Centre National de Référence des Leishmanioses, Montpellier, France

2. Centre Hospitalier Universitaire (Academic Hospital Centre) / University Nice Sophia Antipolis, Laboratoire de ParasitologieMycologie, CHU de Nice, Nice, France

3. Centre Hospitalier Universitaire (Academic Hospital Centre) / Laboratoire de Parasitologie-Mycologie, CHU La Timone, Marseille, France

4. Centre Hospitalier Universitaire (Academic Hospital Centre) / University Paris 6, Laboratoire de Parasitologie-Mycologie, Groupe Hospitalier Pitié-Salpêtrière, Paris, France

5. Centre Hospitalier Universitaire (Academic Hospital Centre) / University Rennes 1, Laboratoire de Parasitologie-Mycologie, CHU de Rennes, Rennes, France

6. The members of the Working Group for the Notification of Human Leishmanioses in France are listed at the end of the article

Citation style for this article:

Lachaud L, Dedet JP, Marty P, Faraut F, Buffet P, Gangneux JP, Ravel C, Bastien P, the Working Group for the Notification of Human Leishmanioses in France.

Surveillance of leishmaniases in France, 1999 to 2012. Euro Surveill. 2013;18(29):pii=20534. Available online: http://www.eurosurveillance.org/ViewArticle. aspx?Articleld $=20534$

Article submitted on 22 August 2012 / published on 18 July 2013

Leishmaniasis is endemic in the south of France, where autochthonous disease is caused by Leishmania infantum, and affects both humans and dogs. The prevalence of canine leishmaniasis is between 3 and $66 \%$ depending on the region and the methods used. Human leishmaniases are also imported into France, mainly from French Guiana and North Africa. The surveillance of autochthonous and imported human leishmaniases is based on passive notification to the National Reference Centre for Leishmaniases (NRCL) created in 1998. Between 1999 and 2012, 317 autochthonous and 1,154 imported cases were notified to the NRCL. The average number of autochthonous cases notified per year was 22.6, mainly cases of visceral leishmaniasis (84.5\%). All cases were infected in the south of France. Leishmaniasis incidence is 0.22 per 100,000 inhabitants in the endemic area. Imported cases were more frequent (annual mean of 82.4 cases) and consisted predominantly in cutaneous leishmaniasis (CL) cases (91\%), essentially L. major CL imported from Maghreb and Sub-Saharan Africa, and L. guyanensis CL from French Guiana. This national notification system allowed a better understanding of the incidence and distribution of the disease; it is also useful to assess the temporal-spatial evolution of the disease in France, which appears relatively stable.

\section{Introduction}

In Europe, leishmaniasis is a zoonosis endemic in countries surrounding the Mediterranean Basin. In France, the French Ministry of Health supported the creation of the National Reference Centre for Leishmaniases (NRCL) in 1998 in Montpellier (http://www.parasitologie.univmontp1.fr/english_vers/en_index.htm), with the aim of better understanding the epidemiological situation of the human disease at the national level. Its true incidence was unknown and the suspected increase of imported cases and of cases in immunocompromised patients needed to be confirmed. In this context, one of the first activities of the NRCL was to set up a system for notifying autochthonous and imported human leishmaniasis cases in France. This retrospective study reports the results of fourteen years of this surveillance.

\section{Epidemiological situation of \\ leishmaniases in France}

In France, the endemic area of leishmaniases is restricted to the south of the country. Several foci are clearly identified along the Mediterranean coast from the Spanish to the Italian border: the eastern Pyrénées, the Cévennes, the Provence, the Alpes-Maritimes and Corsica. The transmission is generally rural but two large cities, Nice and Marseille, are known to comprise endemic foci within their boundaries $[1,2]$. Dogs constitute the main reservoir of the pathogen, and Leishmania infantum is the species responsible for all autochthonous cases. Human cases due to this species are reported every year. However, symptomatic visceral leishmaniasis (VL) human cases represent only 'the tip of the iceberg' [3]. Indeed, individuals living in endemic areas of $L$. infantum are frequently exposed to biting by the sandfly vector. Epidemiological studies conducted worldwide in endemic areas of $L$. infantum and using leishmanin skin test, serology, blood cultivation or polymerase chain reaction (PCR), strongly suggest that the frequency of asymptomatic carriers is high [reviewed in 3].

Before 1999, there was no established notification of human leishmaniasis cases to the French health system. It was therefore difficult to have a precise picture of the incidence and prevalence of leishmaniases in France. Yet, the mean annual incidence of autochthonous VL in France was estimated for the years from 1989 to 1995 at around 1.3, 0.66 and 0.22 cases per 
100,000 inhabitants for the foci in the PyrénéesOrientales, the Alpes-Maritimes and the Cévennes, respectively [1,4]; however, these values do not reflect the strong variations between micro-foci, which can be evidenced using classical [5] or modern [2, 6, unpublished data] epidemiological tools.

\section{The phlebotomine sandfly vector}

In France, the disease is spread by sandflies of the genus Phlebotomus, specifically $P$. perniciosus and $P$. ariasi, which have a seasonal activity, generally from May/June to September/October [7,8]. In southern France, $P$. perniciosus represents the most common vector species: it is mainly present in rural and in periurban areas and preferentially at altitudes less than $600 \mathrm{~m}$ above sea level. P. ariasi, in contrast, is found preferentially in rural areas at altitudes between 200 and $1,400 \mathrm{~m}$ above sea level; it represents the main vector in the Cévennes and Pyrénées-Orientales foci [9, reviewed in 10].

\section{The canine reservoir}

Canine leishmaniasis, affecting essentially the domestic dog (Canis familiaris), is endemic in the regions confined by a triangle of which the apex corresponds to the departments (French administrative territorial divisions) of Ardèche and Drôme and the base to the Mediterranean coast. Two national surveys, performed in 1987 and 2004 and exclusively based on reports from veterinary clinics $[11,12]$, led to the creation of a map displaying the endemic geographical areas and the changing profile of the disease, by comparing maps over an interval of almost 20 years. The information was completed by a retrospective database search and mapping about canine leishmaniasis covering the period 1965 to 2007 [13]. The results show that the disease is still prevalent in southern France, including Ardèche, and that new endemic areas emerge, contiguous to pre-existing endemic foci. Overall, 25 of 95 departments are affected; but for several of them, very low numbers of cases were reported $[13,14]$, questioning the endemic nature of the disease in these areas and reducing the main endemic region to the 12 departments closest to the Mediterranean Sea. The seroprevalence in dogs in the latter ranges from 8.1 to $28 \%$ [11, reviewed in 1].

In the Cévennes focus, a study conducted in 1997, showed that among 253 domestic dogs tested serologically, $29.6 \%$ were positive and $70 \%$ of them presented clinical signs of leishmaniasis [6]. However, in the same survey, using an ultrasensitive PCR assay, the overall prevalence of parasite carriage was found at $80 \%$; and at least $65 \%$ of asymptomatic dogs were found harbouring circulating parasites in their blood [6]. Thus, asymptomatic dogs can act as a reservoir of the parasite and seem to allow the transmission and spread of leishmaniasis [reviewed in 15-17]. Another study modelling previous surveys of canine leishmaniasis estimated the prevalence between 5.4 and $20.3 \%$ [18].

\section{Human cases}

It is not easy to get an accurate picture of the disease progression in humans in southern France during the twentieth century [1]. According to literature data, at least 200 cases of leishmaniasis were recorded between 1918 and 1975, and a further 22 cases from 1975 to 1984 and 65 cases from 1985 to 1992 [unpublished data, 1, 4, 19]. To our knowledge, a single attempt was made in the past to prospectively record all national cases of VL during two years (1986-87) [20]: a total of 89 patients were recorded, of which 70 acquired the disease in France.

The objectives of the present study are to update these data and to report the results obtained by the NRCL in the surveillance of the human disease in France between 1999 and 2012.

\section{Methods}

All leishmaniasis cases notified in France between 1999 and 2012 were analysed according to the place of infection, clinical presentation of the disease, age and risk factors for immunosuppression. For reasons of data completeness, only the period from 2007 to 2012 was analysed for risk factors.

French Guiana (a French overseas territory located in South America) is an endemic area for leishmaniasis [21-23]. Although the Parasitology-Mycology Department of the University Hospital of Cayenne is associated with the NRCL, the focus of the analyses presented here is Europe, and thus cases diagnosed in French Guiana are not included in this study. However, cases imported from French Guiana and diagnosed in France are included.

Cases confirmed by at least one specific biological test could be notified to the CNRL. Data were obtained via the standard reporting form created in 1998 at the NRCL. This form is available online (http://www.parasitologie.univ-montp1.fr/doc/Declaration_pub_2011. pdf) and can be sent back after anonymisation of the data, by mail or email but it cannot be filled online. The notification is not compulsory. It is made on a voluntary basis and relies mainly on care facilities supporting patients. The following characteristics are specified on the form: age (children defined as $\$ 16$ years old), sex, risk factors with particular reference to immunosuppressive conditions such as organ or bone marrow transplantation, human immunodeficiency virus (HIV) infection, immunosuppressive therapy, leukaemia, solid organ cancer, clinical features (for VL: pancytopenia, splenomegaly, hepatomegaly, fever, weight loss; for $\mathrm{CL}$ or MCL: number of lesions, localisation, type of lesions such as ulceration, nodule) duration of symptoms, the presumed place of infection and laboratory tests performed for diagnosis.

\section{Results}

During a period of 14 years between 1999 and 2012, the NRCL received notifications of 317 and 1,142 
Notified autochthonous and imported leishmaniasis cases, France, 1999-2012 (n=1,471)

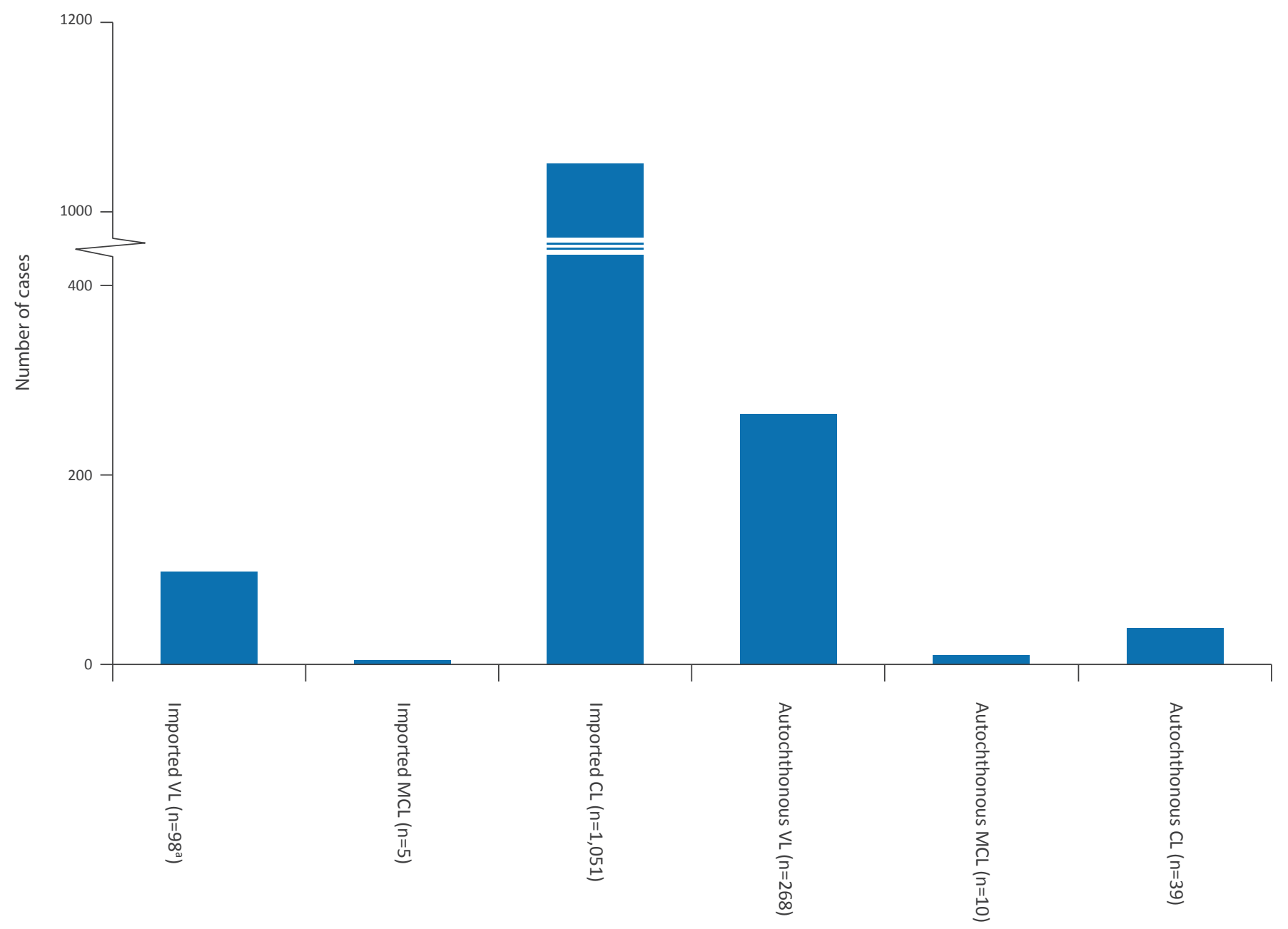

CL: cutaneous leishmaniasis; MCL: mucocutaneous leishmaniasis; VL: visceral leishmaniasis.

a Including 12 VL cases of undetermined origin.

autochthonous and imported cases of leishmaniasis, respectively, as well as 12 (visceral) cases of undetermined origin (Figure 1). More than 70 health centres notified cases: they were mostly university hospital centres but also general hospital centres, the health services of the French army, and occasionally private medical clinics or even a few practitioners.

\section{Autochthonous human leishmaniasis cases}

Of the 317 cases of autochthonous leishmaniasis 268 (84.5\%) were VL cases, 39 (12.3\%) cutaneous leishmaniasis (CL) and 10 (3.1\%) mucocutaneous leishmaniasis (MCL) cases.

The ratio of men to women was 1.8 and the disease affected mostly adults (222 cases; $70 \%$ ); among those, 50 were over 60 years old; 73 patients (23\%) were less than five years old; the mean age of the patients was 35.5 years and the median 39 years (range1 to 89 years).

Figure 2 shows the number of autochthonous annual cases from 1999 to 2012 according to the clinical presentation. For the whole metropolitan France, the average number of notified cases per year was 22.6 (ranging from 14 in 2010 to 35 in 2001). Infection occurred in the south of France in all cases. The mean annual incidence of leishmaniasis that may be inferred from these data is 0.21 per 100,000 inhabitants for the endemic area and 0.26 for the eight most affected departments (Figure 3); it varies from 0.64 (Alpes Maritimes) to 0.01 (Aude) per 100,000 inhabitants.

\section{Visceral leishmaniasis cases}

VL was the predominant clinical presentation (268/317; $84.5 \%$ ), with a mean of 19.1 (ranging from 5 to 31 ) cases per year, and a peak at 32 VL cases in 2001. The two 


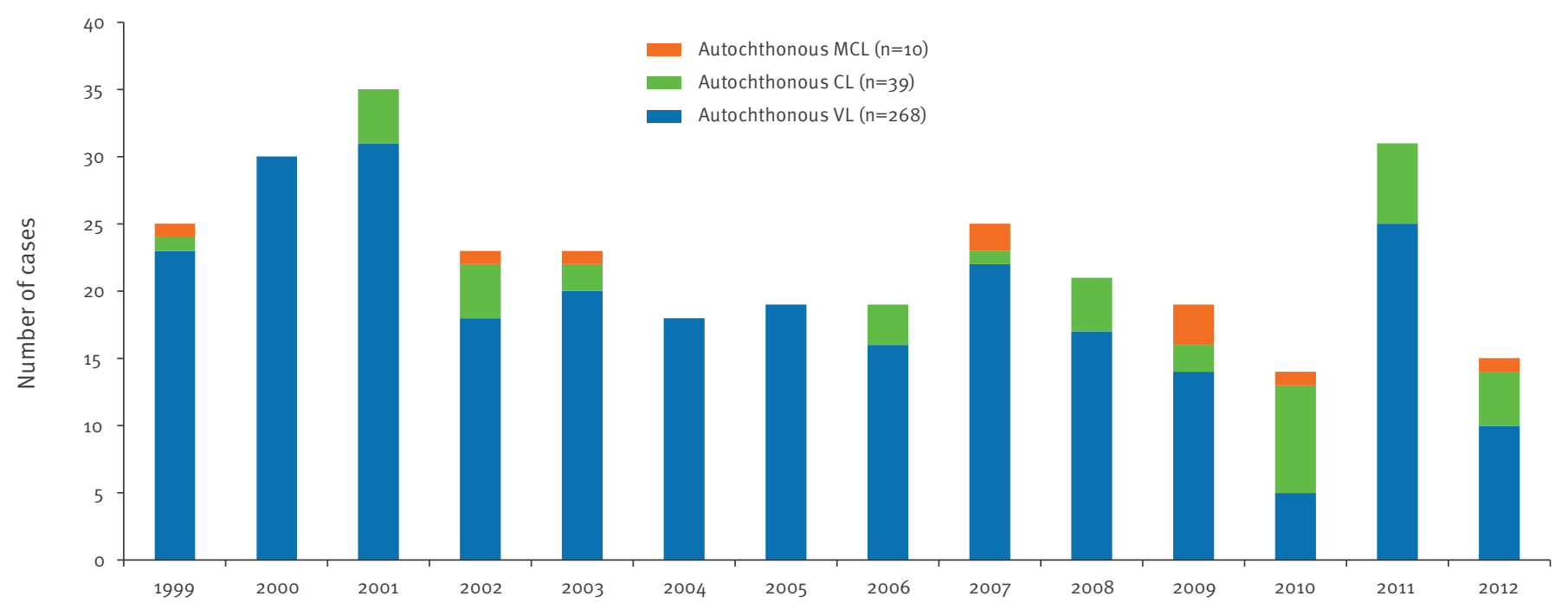

CL: cutaneous leishmaniasis; MCL: mucocutaneous leishmaniasis; VL: visceral leishmaniasis.

departments with the highest number of notified VL cases are the Alpes-Maritimes (97 cases) and Bouchesdu-Rhône (46 cases) (Figure 3).

An analysis of our data over the period 2007 to 2012 shows that VL cases occurred in $62 \%(90 / 145)$ in men and more frequently $(46.9 \% ; 68 / 145)$ in the age group 20 to 60 years; $19.3 \%(28 / 145)$ of the cases were observed in people over 60 years (Figure 4).

Cutaneous leishmaniasis and mucocutaneous leishmaniasis cases

Since 1999 , only 39 cases of CL and 10 of MCL have been reported. Autochthonous $\mathrm{CL}$, with a mean of 2.8 cases (ranging from o to 8) per year. With respect to $M C L$, only 10 cases have been reported, including three from Eastern Pyrénées. MCL was essentially a primary condition of mucosae, with neither visceral, nor purely cutaneous involvement.

\section{Imported leishmaniasis cases}

Between 1999 and 2012, 1,154 imported cases were reported to the NRCL, a mean of 82.4 cases (range 37 to 148 ) annually. Only 98 of these were VL cases, resulting in an annual mean of seven cases. CL cases represented $91 \%(1,051 / 1,154)$ of the total: $41.9 \%(440 / 1,051)$ of these were from Africa, originating from North Africa in $30.9 \%(325 / 1,051)$ of cases and in sub-Saharan Africa in $11 \%(115 / 1,051)$. Imported CL cases acquired in French Guiana represented $41.7 \%(438 / 1,051)$ of the notified cases (only 44 cases, $4.2 \%$ of them having been infected in the rest of Latin America). These three geographical areas correspond to the main migratory movements to metropolitan France.
Molecular strain typing from the Old World cases for the years 2009 to 2011, identified a large majority (141 cases; $88 \%$ ) of L. major, followed by L. tropica (18 cases; $11 \%)$; for the New World cases, L. guyanensis was largely predominant (170 cases; $83 \%$ ), followed by $L$. braziliensis ( 27 cases; $13 \%$ ). It is of note that imported cases from French Guiana reported to the NRCL are not necessarily representative of the epidemiological situation of this region.

\section{Autochthonous and imported visceral leishmaniasis cases and immunocompromising conditions}

Taking into account all VL cases $(n=366)$ reported to the NRCL from 1999 to 2012, 268 autochthonous cases and 98 imported cases, data analysis showed the association of an immunocompromising condition in $44.3 \%$ of cases (162/366): 31.4\% (115/366) were HIV infected, $9.6 \%(35 / 366)$ had an immunosuppressive treatment and $3.3 \%(12 / 366)$ had received an organ or bone marrow transplant.

\section{Discussion and conclusion}

In France, autochthonous leishmaniasis is due to L. infantum and is endemic mainly in the Mediterranean region. Canine leishmaniasis remains widespread in these foci and is the subject of studies by the ANSES (National Agency for Health Security of Food and Environment) as well as several national veterinary (Lyon, Maisons-Alfort, Nantes) or medical (Nice, Marseille) faculties, often in collaboration with the NRCL. With respect to human cases, the creation of a notification system at the NRCL in 1999 has allowed a better understanding of the incidence and distribution 
Cumulative number of notified autochthonous visceral leishmaniasis cases in the most affected departments in France, 1999-2012 $(\mathrm{n}=268)$

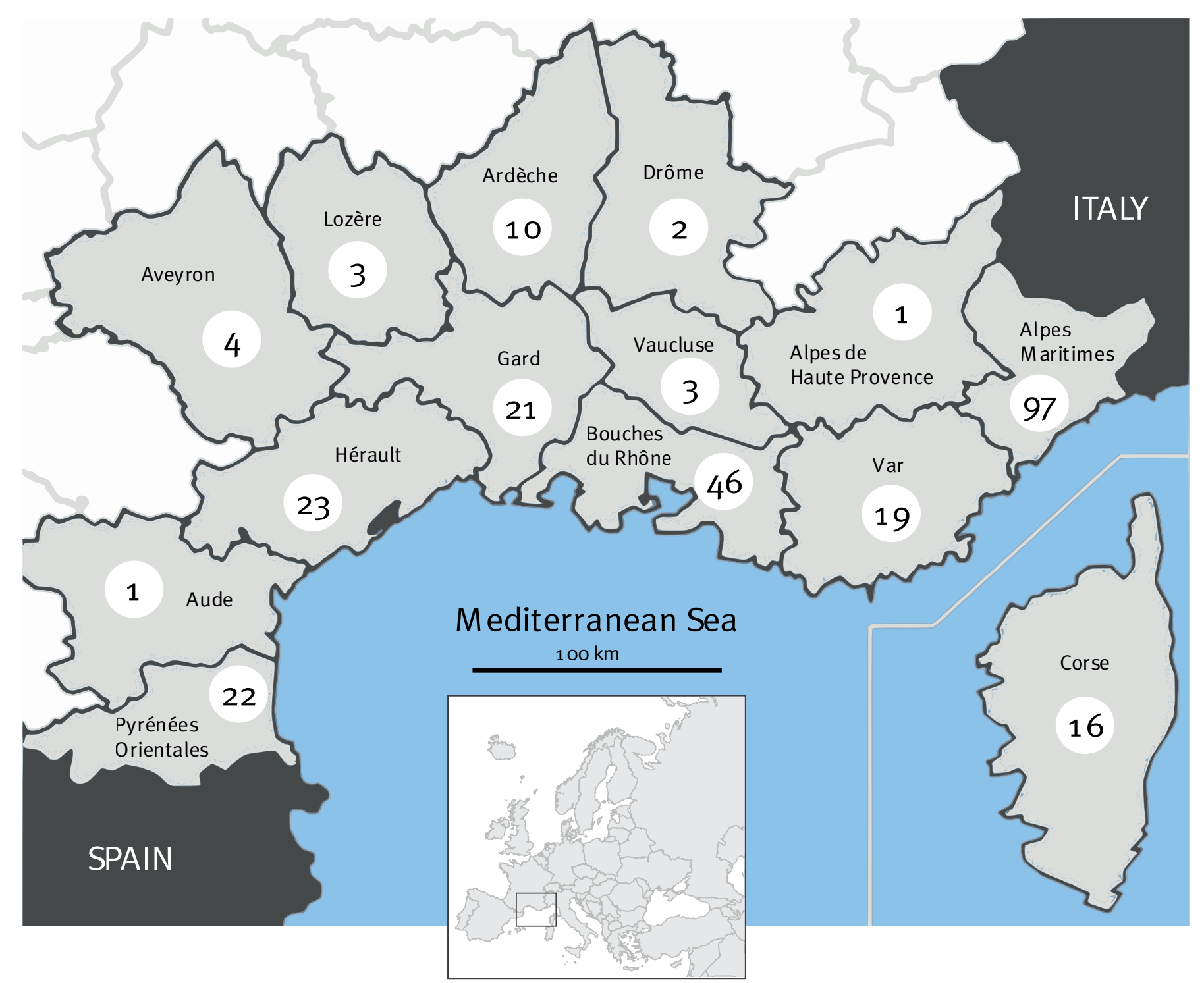

of the disease. Although an increase in incidence or an extension of the endemic areas can be anticipated in view of global warming $[24,25]$, it appears that autochthonous cases remain relatively rare (annual mean 22.6) in France with a clear predominance of VL (84.5\%).

VL has long been considered a disease of young children. The first case of Mediterranean kala-azar in a child in France was reported in 1918 [26]. A national survey conducted in 1986-87 showed a predominance of the disease in children, which constituted $51 \%$ of cases, with equal distribution between both sexes [20]. However, over the last decades, with the emergence of immunosuppression and primarily of HIV / acquired immunodeficiency syndrome (AIDS), the epidemiology of the disease has changed: in particular, the incidence in adults has increased significantly. Indeed, between
1975 and 2004 , children accounted for only $30 \%$ of the cases [1]. This can be partly correlated with the increasing number of cases of leishmaniasis/HIV coinfection: HIV-positive patients are at high risk, and leishmaniasis is considered an opportunistic disease [27,28]. Between 1996 and 1998, 50\% of new VL cases in southwestern Europe (including France) involved HIV-positive patients [27]. The mean age in our adult patients with VL was 36 years [28]. Nevertheless, the occurrence of cases among the elderly was not exceptional, which may be explained by ageing, declining of immune system, association with other pathologies such as tumours, inflammatory diseases, VL can also affect patients with no apparent immunosuppression nor risk factor, irrespective of their age. Overall, the incidence of VL during the study period was relatively stable, but a decrease of the incidence can be noted if compared to the period from 1993 to $1997[1,2]$, this 


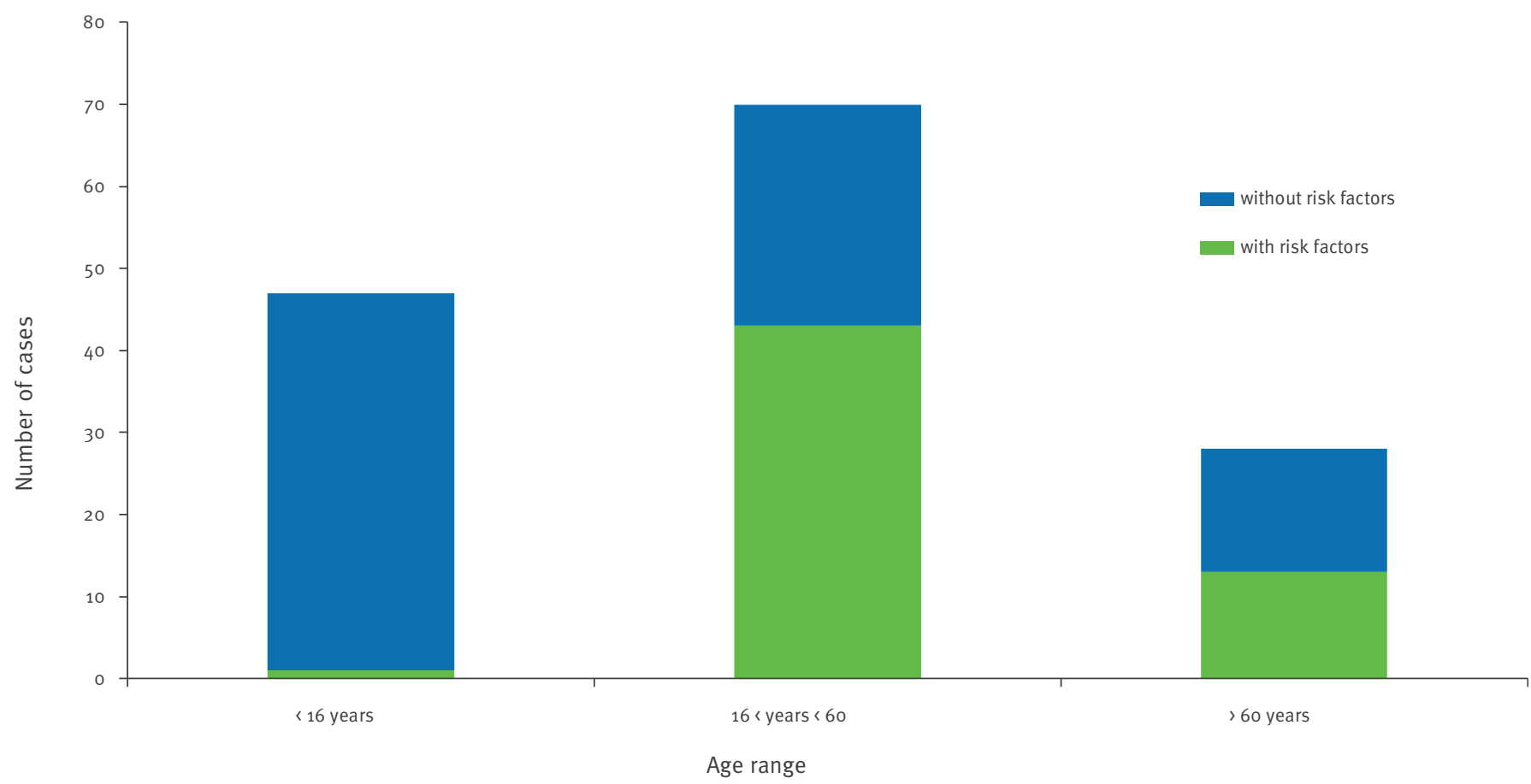

For reasons of completeness of the data, only 2007-2012 was analysed for risk factors.

being most likely linked with the introduction of highly active antiretroviral therapy in AIDS patients.

In contrast to $\mathrm{VL}$, autochthonous cases of $\mathrm{CL}$ and $M C L$ are rare in France [29] and appear sporadic. $C L$ is probably underdiagnosed and certainly undernotified, to a great extend because cutaneous lesions due to L. infantum are often small, painless and spontaneously self-curing within a few months; hence these benign lesions are essentially seen by general practitioners or dermatologists, which generally do not notify cases. The number of MCL cases notified to the NRCL, however, reflects almost the whole of the total seen in France, as this atypical clinical presentation necessitates the implementation of a specific laboratory diagnosis and initiation of anti-Leishmania drug treatment.

Compared to autochthonous cases, the number of imported cases is relatively high with an annual mean of 82.4 cases, mainly consisting in CL cases due to $L$. major and L. guyanensis, while for VL cases the annual mean of seven is not far from the nine cases per year reported in 1986-87 [20].

The monitoring by the NRCL is also useful to assess the temporal-spatial evolution of the disease. It is difficult to infer from these data whether the incidence of autochthonous leishmaniasis is declining in France or not: certain data sets suggest a medium-term (over decades) tendency to decline $[1,2,20]$, but our data show that it is currently relatively stable. As to the risk of seeing the emergence of 'exotic' or hybrid parasites
[30] which would be transmitted locally by permissive phlebotomine vectors, we consider that it is almost null. Indeed, (i) there is no evidence for any permissivity of $P$. perniciosus and $P$. ariasi; (ii) the probability of this occurring in nature appears extremely low, as, on top of permissivity, it requires gathering a number of factors allowing transmission (southern France, summer season, absence of treatment, etc.).

The Working Group for the Notification of Human Leishmanioses in France

(In alphabetical order and in addition to the main authors) Y Balard (Centre National de Référence des Leishmanioses, Montpellier), P Delaunay (CHU Nice), S Hamane (CHU Saint Louis, Paris), H Yéra (CHU Cochin, Paris), S Houzé (CHU Bichat, Paris), A Izri (CHU Avicenne, Paris), E Lightburne (Services de Santé des Armées Lavéran, Marseille), Charles Mary (CHU La Timone, Marseille), Gloria Morizot (Institut Pasteur, Paris), Tiphaine Merguey (CHU de Rennes), Renaud Piarroux (CHU La Timone, Marseille), Christelle Pomares (CHU Nice), Francine Pratlong (Centre National de Référence des Leishmanioses, Montpellier), Claudine Sarfati (CHU Saint Louis, Paris).

\section{Acknowledgements}

We warmly thank all the centers who notified leishmaniasis cases to the NRCL over the whole of this period, and regret not to be able to name all our correspondents individually. We also acknowledge the technical help of Patrick Lami and Loïc Talignani for in vitro cultivation, of Ghislaine Serres for molecular identification of the strains and of Yves Balard for creating the distribution maps. 


\section{Conflict of interest}

None declared.

\section{References}

1. Marty P, Izri A, Ozon C, Haas P, Rosenthal E, Del Giudice P, et al. A century of leishmaniasis in Alpes-Maritimes, France. Ann Trop Med Parasitol. 2007;101(7):563-74. PMid:17877875.

2. Faucher B, Gaudart J, Faraut F, Pomares C, Mary C, Marty $P$, et al. Heterogeneity of environments associated with transmission of visceral leishmaniasis in South-Eastern France and implication for control strategies. PLoS Negl Trop Dis. 2012; 6(8):1765. http://dx.doi.org/10.1371/journal. pntd.0001765. PMid:22880142. PMCid:PMC3413717.

3. Michel G, Pomares C, Ferrua B, Marty P. Importance of worldwide asymptomatic carriers of Leishmania infantum ( $\mathrm{L}$. chagasi) in human. Acta Trop. 2011;119(2-3):69-75. http:// dx.doi.org/10.1016/j.actatropica.2011.05.012. PMid:21679680.

4. Bassenne I, Pratlong F, Dereure J, Balard Y, Dedet JP. [Human leishmaniasis in Cévennes: retrospective study, 1933-1994]. Med Mal Inf. 1996;26(1):1-5. French. http://dx.doi.org/10.1016/ So399-077X(96)80256-3

5. Rioux JA, Killick-Kendrick R, Périères J, Turner DP, Lanotte G. [Ecology of leishmaniases in Southern France. 13. Middle slopes of hillsides as sites of maximum risk of transmission of visceral leishmaniasis in the Cévennes]. Ann Parasitol Hum Comp. 1980;55(4):445-453. French. PMid:7458169.

6. Lachaud L, Chabbert E, Dubessay P, Dereure J, Lamothe J, Dedet JP, et al. Value of two PCR methods for the diagnosis of canine visceral leishmaniasis and the detection of asymptomatic carriers. Parasitology. 2002;125(3):197207. http://dx.doi.org/10.1017/So031182002002081. PMid:12358417.

7. Rioux JA, Golvan YJ, Croset H, Houin R, Juminer B, Bain 0 , et al. [Ecology of leishmaniases in Southern France. 1. Sandflies. Sampling. Ethnology]. Ann Parasitol Hum Comp. 1967;42(6):561-603. French. PMid:5630232.

8. Killick-Kendrick R. Phlebotomine vectors of the leishmaniases: a review. Med Vet Entomol. 1990;4(1):1-24. http://dx.doi. org/10.1111/j.1365-2915.1990.tbo0255.x. PMid:2132963.

9. Rioux JA, Perieres J, Killick-Kendrick R, Lanotte G, Bailly M. [Ecology of leishmaniasis in south France. 17. Sampling of Phlebotomus by the method of adhesive traps. Comparison with the technique of capture on human bait]. Ann Parasitol Hum Comp. 1982;57(6):631-5. French. PMid:7168533.

10. Dedet, JP. [Leishmaniases in France]. Bull Epid Hebd Hors-série 2010;14:9-12. French.

11. Bourdeau P, Groulade P. [Results of the survey about leishmaniasis]. Pratique Méd Chir Animal Compagnie. 1988;5(1):5-10. French.

12. Coulibaly E, Heinis V, Campos C, Ozon C, Bourdoiseau G, Haas $P$, et al. [Survey about diagnostic and therapeutic practices for leishmaniasis in veterinary practitioners in 2000]. Epidémiol Santé anim. 2004;45(1):33-44. French.

13. Chamaillé L, Tran A, Meunier A, Bourdoiseau G, Ready P, Dedet JP. Environmental risk mapping of canine leishmaniasis in France. Parasit Vectors. 2010;8:3:31.

14. Houin R, Jolivet G, Combescot C, Deniau M, Puel F, Barbier D et al. [Preliminary study of a canine leishmaniasis focus in the region of Tours] . In: Colloque Ecologie des leishmanioses, 18-24 Août 1974, Montpellier: CNRS Editions, 1977;109-115. French.

15. Marty P, Pomares C, Michel G, Delaunay P, Ferrua B, Rosenthal E. [Mediterranean visceral leishmaniasis]. Bull Acad Natl Med. 2011;195(1):181-8. French. PMid:22039711.

16. Laurenti MD, Rossi CN, Matta VL, Tomokane TY, Corbett CE, Secundino NF, et al. Asymptomatic dogs are highly competent to transmit Leishmania (Leishmania) infantum chagasi to the natural vector. Vet Parasitol. 2013; doi:pii: S03044017(13)00162-3. 10.1016/j.vetpar.2013.03.017.

17. Molina R, Amela C, Nieto J, San-Andrés M, González F, Castillo JA, et al. Infectivity of dogs naturally infected with Leishmania infantum to colonized Phlebotomus perniciosus. Trans R Soc Trop Med Hyg. 1994 ; 88(4):491-493. http://dx.doi. org/10.1016/0035-9203(94)90446-4.

18. Franco AO, Davies CR, Mylne A, Dedet JP, Gállego M, Ballart $C$, et al. Predicting the distribution of canine leishmaniasis in western Europe based on environmental variables. Parasitology. 2011;14:1-14.

19. Marty P, Delaunay P, Pratlong F, Gari-Toussaint M, Haas H, Rosenthal $E$, et al. [Infantile visceral leishmaniasis in Alpes Maritimes, 1975-2004]. Bull Epid Hebd. 2006;17:115-17. French.
20. Jeannel D, Tuppin P, Brucker G, Danis M, Gentilini M. Imported and autochthonous kala-azar in France. British Med J 1991;303(6798):336-338. http://dx.doi.org/10.1136/ bmj.303.6798.336. PMid:1912774. PMCid:PMC1670795.

21. Rotureau B, Ravel C, Nacher M, Couppié P, Curtet I, Dedet JP, et al. Molecular epidemiology of Leishmania (Viannia) guyanensis in French Guiana. J Clin Microbiol. 2006;44(2):468-73. http:// dx.doi.org/10.1128/JCM.44.2.468-473.2006. PMid:16455900. PMCid:PMC1392701.

22. Rotureau B, Couppié P, Nacher M, Dedet JP, Carme B. [Cutaneous leishmaniases in French Guiana]. Bull Soc Pathol Exot. 2007;100(4):251-60. French. PMid:17982853.

23. Simon S, Veron V, Carme B. Leishmania spp. identification by polymerase chain reaction-restriction fragment length polymorphism analysis and its applications in French Guiana. Diagn Microbiol Infect Dis. 2010;66(2):175-80. http://dx.doi. org/10.1016/j.diagmicrobio.2009.08.013. PMid:19782495.

24. Maroli M, Rossi L, Baldelli R, Capelli G, Ferroglio E, Genchi $C$, et al. The northward spread of leishmaniasis in Italy: evidence from retrospective and ongoing studies on the canine reservoir and phlebotomine vectors. Trop Med Int Health. 2008;13(2):256-64. http://dx.doi.org/10.1111/j.1365 3156.2007.01998.x. PMid:18304273.

25. Dereure J, Vanwambeke SO, Malé P, Martinez S, Pratlong $F$, Balard Y, et al. The potential effects of global warming on changes in canine leishmaniasis in a focus outside the classical area of the disease in southern France. Vector Borne Zoonotic Dis. 2009;9(6):687-94. http://dx.doi.org/10.1089/ vbz.2008.0126. PMid:19271999.

26. Labbé M, Targhetta I, Ameuille P. [Infantile kaka-azar in France]. Bull Acad Med. 1918;79:288-90. French.

27. Alvar J, Ca-avate C, Gutiérrez-Solar B, Jiménez M, Laguna $F$, López-Vélez R, et al. Leishmania and human immunodeficiency virus coinfection: the first 10 years. Clin Microbiol Rev. 1997;10(2):298-319. PMid:9105756. PMCid:PMC172921.

28. Bourgeois N, Lachaud L, Reynes J, Rouanet I, Mahamat A, Bastien P. Long-term monitoring of visceral leishmaniasis in patients with AIDS: relapse risk factors, value of polymerase chain reaction, and potential impact on secondary prophylaxis. J Acquir Immune Defic Syndr. 2008;48(1):13-9. http://dx.doi. org/10.1097/QAl.ob013e318166af5d. PMid:18300698.

29. Faucher B, Pomares C, Fourcade S, Benyamine A, Marty P, Pratlong L, et al. Mucosal Leishmania infantum leishmaniasis: specific pattern in a multicentre survey and historical cases. J Infect. 2011;63(1):76-82. http://dx.doi.org/10.1016/j. jinf.2011.03.012. PMid:21658772.

30. Volf P, Benkova I, Myskova J, Sadlova J, Campino L, Ravel C. Increased transmission potential of Leishmania major/ Leishmania infantum hybrids. Int J Parasitol. 2007; 37(6):58993. http://dx.doi.org/10.1016/j.ijpara.2007.02.002 PMid:17376453. PMCid:PMC2839924. 